\title{
Preparation and characterization of oyster shell powder- treated rice husk ash adsorbent pellet for As(III) removal
}

\author{
Pichnipa Khownpurk and Walairat Chandra-ambhorn* \\ Department of Chemical Engineering, Faculty of Engineering, King Mongkut's Institute of Technology Ladkrabang, 1 Soi \\ Chalongkrung 1, Ladkrabang, Bangkok 10520, Thailand
}

\begin{abstract}
The adsorbent pellet for As(III) removal was prepared from ground oyster shell and rice husk ash. The effects of particle size of oyster shell powder (OS) and the ratio between the OS and Treated rice husk ash (TRHA) on the stability of the adsorbent pellet were studied. The adsorbent pellet was characterized by XRD, XRF and SEM. The solubility and As(III) adsorption tests were performed. The results showed that the adsorbent pellet prepared from OS size $<106 \mu \mathrm{m}$ with OS:TRHA ratio of 0.7:0.3 could provide As(III) maximum adsorption capacity of approximately $26.20 \mathrm{mg} / \mathrm{g}$. Furthermore, the XRD and SEM results indicated that the adsorbent pellet could consist of two parts i.e. $\mathrm{CaO}$ that could adsorb $\mathrm{As}(\mathrm{III})$ in the form of $\mathrm{Ca}-\mathrm{As}-\mathrm{O}$ and the $\mathrm{CaSiO}_{3}$ and $\mathrm{C}-\mathrm{S}-\mathrm{H}$ compounds which behaved as a binder to bind the precursor powders to be stable adsorbent pellet without cracking.
\end{abstract}

\section{Introduction}

Arsenic is a hazardous element that contaminated in soil and water. It was reported that the toxicity of arsenic could cause the human health problem such as cancer, pigmentation changes, neurological disorder etc.[1-4]. In Thailand, more than 25 provinces are affected by the arsenic pollution such as Suphanburi province and Ubon Ratchathani [5, 6]. Furthermore, almost of arsenic contaminated in water exists in two forms; arsenite $(\mathrm{As}(\mathrm{III}))$ and arsenate $(\mathrm{As}(\mathrm{V}))$. It was also reported that the As(III) was much more toxic and more difficult to remove than $\mathrm{As}(\mathrm{V})$ [7].

Adsorption is an effective method for removing arsenic from contaminated water. It was reported in the previous work that the calcine oyster shell powder (COS) could be used as the adsorbent to remove the As(III) from contaminated water with the maximum As(III) adsorption capacity approximately $195.5 \mathrm{mg} / \mathrm{g}$ (pH 11) [8]. However, fine powder of COS is difficult to separate from treated water.

The industrial crops in Thailand caused a lot of waste rice husk ash (RHA). It was reported that RHA was mainly contained $\mathrm{SiO}_{2}$ [9] which could react with $\mathrm{Ca}(\mathrm{OH})_{2}$ and form calcium silicate hydrate compound (C-S-H) called the pozzolanic reaction. The C-S-H compound could improve the strength of concreate $[10$, $11]$.

This research aims to develop the As(III) adsorbent pellet in order to be easily separated from treated water after used by using oyster shells and RHA as raw materials. In this work, the oyster shell powder (OS) was blended with treated rice husk ash (TRHA) and pelletized by using the metal mould. The effects of OS particle size and ratio between OS and TRHA on the stability of the adsorbent pellet and adsorption performance were investigated.

\section{Materials and methods}

\subsection{Adsorbent pellet preparation}

The adsorbent pellets were prepared from oyster shells and rice husk ash (RHA) obtained from Chanthaburi province and a power plant in Thailand, respectively. Firstly, the treated rice husk ash (TRHA) was prepared by calcining RHA at $600{ }^{\circ} \mathrm{C}$ in air for $13 \mathrm{~h}$. Oyster shells were washed, dried, ground and sieved to obtain the oyster shell powder (OS) with the particle sizes $<106$ $\mu \mathrm{m}, 106-150 \mu \mathrm{m}$ and 150-250 $\mu \mathrm{m}$. Secondly, OS and TRHA were weighed and mixed in various ratios. Then, distilled water was added into the mixture powder to provide plasticity. Then, the mixture paste was pressed in a pellet metal mould. After that, the pellets were calcined at $700^{\circ} \mathrm{C}$ in air for $8 \mathrm{~h}$. The X-ray fluorescence spectrometer (Bruker model S8 Tiger) was used to evaluate the elemental composition of OS and TRHA. The crystalline phase of the adsorbent pellets was determined by an x-ray diffractometer (XRD 6100, SHIMADZU, Japan) using $\mathrm{Cu}-\mathrm{K} \alpha$ radiation, at $40 \mathrm{kV}$ and $2 \theta$ range from $5-80^{\circ}$ with the scan speed of 2.0 $\% / \mathrm{min}$. The morphologies of the adsorbent pellets before

* Corresponding author: walairat.ch@kmitl.ac.th (Walairat Chandra-ambhorn) 
and after As(III) adsorption were observed by a scanning electron microscope (SEM, Carl Zeiss EVO®MA10).

\subsection{Solubility tests}

The solubility tests of COS and the adsorbent pellet were performed in Erlenmeyer flasks with rubber cork. Firstly, $\mathrm{pH}$ of distilled water was adjusted to 7 by $0.1 \mathrm{M}$ of $\mathrm{NaOH}$ and/or $\mathrm{HCl}$. Next, $\mathrm{COS}$ and the adsorbent pellet were weighed and individually added into the solutions and kept for $24 \mathrm{~h}$. The $\mathrm{pH}$ of solutions were measured by a pH meter (Hanna instrument, HI 98107).

\subsection{As(III) adsorption test}

As(III) adsorption on the adsorbent pellet was performed via batch test. The stock solution of As(III) prepared from $\mathrm{As}_{2} \mathrm{O}_{3}$ was diluted to $100 \mathrm{mg} / \mathrm{L}$ with distilled water. The $\mathrm{pH}$ of the solution was adjusted to 7 by using $0.1 \mathrm{M}$ of $\mathrm{NaOH}$ and/or $\mathrm{HCl}$. Then, the adsorbent pellets were individually added into the Erlenmeyer flasks which contained $100 \mathrm{ml}$ of As (III) solution and kept for $24 \mathrm{~h}$. After that, the adsorbent pellet was removed from the As(III) solution. The concentration of As(III) remaining in the solution was determined by titration with $\mathrm{KMnO}_{4}$. The As(III) adsorption capacity of the adsorbent pellet was calculated by using Equation (1).

$$
\text { As(III) adsorption capacity }\left(q_{t}\right)=\frac{\left(C_{0}-C_{e}\right) V}{W}
$$

where $C_{0}$ and $C_{e}$ are concentrations of $\mathrm{As}(\mathrm{III})$ at initial and at equilibrium $(\mathrm{mg} / \mathrm{L})$, respectively, while $V$ is volume of the solution (L) and $W$ is mass of the adsorbent (g).

\section{Results and discussion}

\subsection{XRF and XRD analysis}

The chemical compositions of OS and TRHA were evaluated by XRF and XRD. The results indicated that $\mathrm{CaCO}_{3}(95.99 \%)$ was the main component of OS while $\mathrm{SiO}_{2}(87.00 \%)$ was the major compound of TRHA. Moreover, the XRD result of TRHA showed the broad smooth hump peak at $2 \Theta$ approximately $22^{\circ}$ (the XRD pattern is not shown in this paper) which indicates that $\mathrm{SiO}_{2}$ in TRHA should exist in amorphous form. Habeeb [12] and Srinivasreddy [13] reported that amorphous $\mathrm{SiO}_{2}$ could react with $\mathrm{Ca}(\mathrm{OH})_{2}$ and form calcium silicate hydrate compound (C-S-H) which could improve the compressive strength in the materials.

The crystalline phases of the adsorbent pellet before and after As(III) adsorption test were determined by using XRD technique. The XRD results [14] showed that the adsorbent pellet before As(III) adsorption composed of calcium silicate $\left(\mathrm{CaSiO}_{3}\right), \mathrm{C}-\mathrm{S}-\mathrm{H}$ compounds, calcium oxide $(\mathrm{CaO})$ and $\mathrm{Ca}(\mathrm{OH})_{2}$. This indicated that after mixing OS with TRHA and water, some of $\mathrm{Ca}(\mathrm{OH})_{2}$, the product produced from the reaction between $\mathrm{CaCO}_{3}$ and water, in OS should react with $\mathrm{SiO}_{2}$ in the TRHA and water and formed $\mathrm{H}_{4} \mathrm{SiO}_{4}$. During the calcination at $700^{\circ} \mathrm{C}$ for $8 \mathrm{~h}, \mathrm{H}_{4} \mathrm{SiO}_{4}$ transformed into $\mathrm{CaSiO}_{3}$ and $\mathrm{C}-\mathrm{S}$ $\mathrm{H}$ insoluble compounds [15] while the remaining $\mathrm{CaCO}_{3}$ in the adsorbent pellet converted into $\mathrm{CaO}$. After the adsorption test, the peaks of $\mathrm{CaO}$ disappeared while the peaks of Ca-As-O were observed. This implies that after the adsorbent pellet was added into As(III) solution, the $\mathrm{CaO}$ changed into $\mathrm{Ca}(\mathrm{OH})_{2}$ and further reacted with $\mathrm{As}$ (III) and formed Ca-As-O. However, the intensities of the XRD peaks of $\mathrm{CaSiO}_{3}$ and C-S-H compounds insignificantly changed. This implies that the $\mathrm{CaSiO}_{3}$ and C-S-H compounds should not react with As(III).

\subsection{The solubility test}

The amounts of dissolved COS and adsorbent pellet reported in terms of dissolved $\mathrm{CaO}$ are presented in Fig 1. It is noted that $\operatorname{COS}<106,106-150$ and $150-250$ in Fig. 1 referred to COS prepared from OS particle size ranges of $<106 \mu \mathrm{m}, 106-150 \mu \mathrm{m}$ and 150-250 $\mu \mathrm{m}$, respectively while pellet $<106,106-150$ and 150-250 referred to adsorbent pellet prepared from OS:TRHA ratio of 0.7:0.3 with OS sizes $<106 \mu \mathrm{m}, 106-150 \mu \mathrm{m}$ and 150-250 $\mu \mathrm{m}$, respectively.

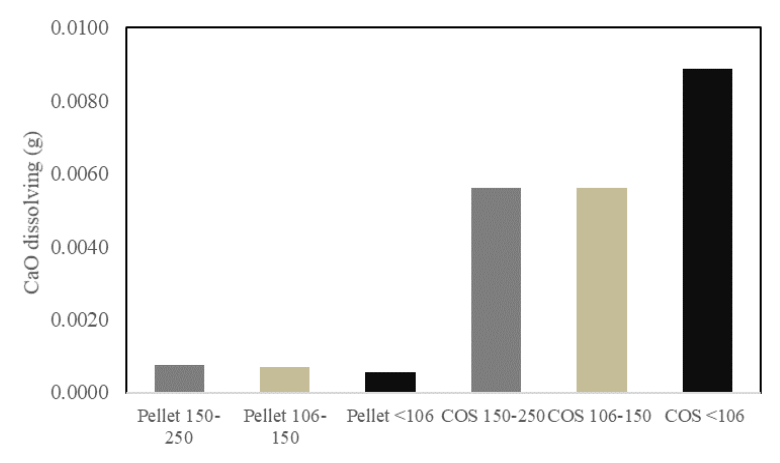

Fig. 1. The amount of $\mathrm{CaO}$ in $\mathrm{COS}$ and in adsorbent pellets dissolved in the solutions.

The solubility tests were performed twice, the error was in the range of $0.00-21.51 \%$. As seen in Fig. 1, the amount of dissolved $\mathrm{CaO}$ in adsorbent pellets were much less than that of COS in all size ranges. This should be because some amount of $\mathrm{CaCO}_{3}$ in the adsorbent pellet precursor transformed into $\mathrm{CaSiO}_{3}$ and $\mathrm{C}-\mathrm{S}-\mathrm{H}$ insoluble compounds causing less $\mathrm{CaO}$ to be produced after calcination and thus less $\mathrm{CaO}$ dissolving in the solution. The other reason is because surface area of the adsorbent pellet is much less than that of COS resulting in less contact of $\mathrm{CaO}$ with water in the solution and therefore less dissolution can occur. As seen in Fig.1, COS prepared from OS size $<106 \mu \mathrm{m}$ had the greatest amount of $\mathrm{CaO}$ dissolved in the solution due to the largest contact area. 


\subsection{Adsorption capacity and pellet stability}

The stability and As(III) adsorption tests of adsorbent pellets were performed in order to find the most appropriate condition for the adsorbent pellet preparation. The results are showed in Table 1.

Table 1. The stability and As(III) adsorption capacity of adsorbent pellets with different conditions.

\begin{tabular}{cccc}
\hline $\begin{array}{c}\text { OS size } \\
(\mu \mathrm{m})\end{array}$ & OS:TRHA & Stability & $\begin{array}{c}\text { Adsorption } \\
\text { capacity } \\
(\mathrm{mg} / \mathrm{g})\end{array}$ \\
\hline & $0: 1.0$ & & 1.38 \\
$<106$ & $1.0: 0$ & & 241.67 \\
$150-250$ & $0.8: 0.2$ & Crack & $42.50 \pm 0.09$ \\
$150-250$ & $0.7: 0.3$ & Crack & $22.38 \pm 2.85$ \\
$150-250$ & $0.6: 0.4$ & Crack & $24.26 \pm 24.23$ \\
$106-150$ & $0.8: 0.2$ & Crack & $35.64 \pm 7.47$ \\
$106-150$ & $0.7: 0.3$ & Crack & $14.02 \pm 0.65$ \\
$106-150$ & $0.6: 0.4$ & Crack & $34.08 \pm 10.65$ \\
$<106$ & $0.8: 0.2$ & Crack & $33.10 \pm 0.41$ \\
$<106$ & $0.7: 0.3$ & Not Crack & $26.20 \pm 2.02$ \\
$<106$ & $0.6: 0.4$ & Not Crack & $19.50 \pm 2.83$ \\
\hline
\end{tabular}

The adsorption tests were performed twice and the As(III) adsorption capacities were reported as the average values. The errors of As(III) adsorption capacity of cracked pellets were in the range of $0.21 \%-62.37 \%$ while un-cracked pellets had the errors of As(III) adsorption in the range of $0.88 \%-15.08 \%$. The greater error of the cracked pellets was because of the uncontrolled cracking patterns of the cracked pellets causing in different area of cracked pieces exposed to the solution. The stability tests of adsorbent pellets showed that the crack of adsorbent pellets prepared from OS sizes 106-150 $\mu \mathrm{m}$ and 150-250 $\mu \mathrm{m}$ with OS:TRHA ratios between 0.8:0.2 and 0.6:0.4 was observed within $30 \mathrm{~min}$ after the adsorbent pellets had been added into the solution while the adsorbent pellets prepared from OS size $<106 \mu \mathrm{m}$ with OS:TRHA ratios of 0.7:0.3 and 0.6:0.4 did not crack even after finishing the adsorption experiment $(24 \mathrm{~h})$. There are two reasons that could explain why the adsorbent pellets prepared from OS size $<106 \mu \mathrm{m}$ with ratio 0.7:0.3 and 0.6:0.4 did not crack. (1) The OS size $<106 \mu \mathrm{m}$ contained the particles with the sizes that small enough to be well compacted and better sintered than the larger ones. After the adsorbent pellets were added into solution, the solution could less diffuse into the denser adsorbent pellets causing lower $\mathrm{CaO}$ to dissolve. (2) The OS size $<106 \mu \mathrm{m}$ had larger surface area that allows the pozzolanic reaction to occur and form the binder substances i.e. $\mathrm{CaSiO}_{3}$ and $\mathrm{C}-\mathrm{S}-\mathrm{H}$ compounds more than the other OS sizes. The $\mathrm{CaSiO}_{3}$ and $\mathrm{C}-\mathrm{S}-\mathrm{H}$ compounds could bind the precursor powder to be stable without cracking. In addition, the crack of the adsorbent pellet prepared from OS size $<106 \mu \mathrm{m}$ with ratio of 0.8:0.2 may occur due to too little TRHA contained in the adsorbent pellet. Then, the adsorbent pellet contained insufficient $\mathrm{CaSiO}_{3}$ and $\mathrm{C}-\mathrm{S}-\mathrm{H}$ compounds to bind the precursor particles in the pellet.

As also seen in Table 1, the As(III) adsorption tests showed that $\mathrm{As}$ (III) adsorption capacity of $\mathrm{COS}<106$ was extremely more than that of TRHA. This indicates that only $\mathrm{CaO}$ should be adsorption sites in the adsorbent pellet. The As(III) adsorption capacity of un-cracked adsorbent pellets were further compared. It can be seen that As(III) adsorption capacity of adsorbent pellet prepared from OS size $<106 \mu \mathrm{m}$ with ratio of 0.7:0.3 was greater than that of the pellet prepared from OS size $<106 \mu \mathrm{m}$ with the ratio of 0.6:0.4. The adsorption result confirmed the previous statement as the amount of $\mathrm{CaO}$ contained in the adsorbent pellet prepared from $\mathrm{OS}<106$ $\mu \mathrm{m}$ with ratio of $0.7: 0.3$ was more than that of the adsorbent pellet prepared from OS size $<106 \mu \mathrm{m}$ with ratio of 0.6:0.4. The results of stability test and As(III) adsorption capacity indicate that the adsorbent pellet prepared from OS $<106 \mu \mathrm{m}$ with ratio of 0.7:0.3 is the most appropriate condition for the adsorbent pellet preparation for As(III) removal.

\subsection{Morphology}

The surface morphologies of the adsorbent pellets prepared from OS sizes $<106 \mu \mathrm{m}, 106-150 \mu \mathrm{m}$ and 150 $250 \mu \mathrm{m}$ with OS:TRHA ratio of $0.7: 0.3$ before and after As(III) adsorption tests were observed by using SEM. The SEM images are illustrated in Fig 2.

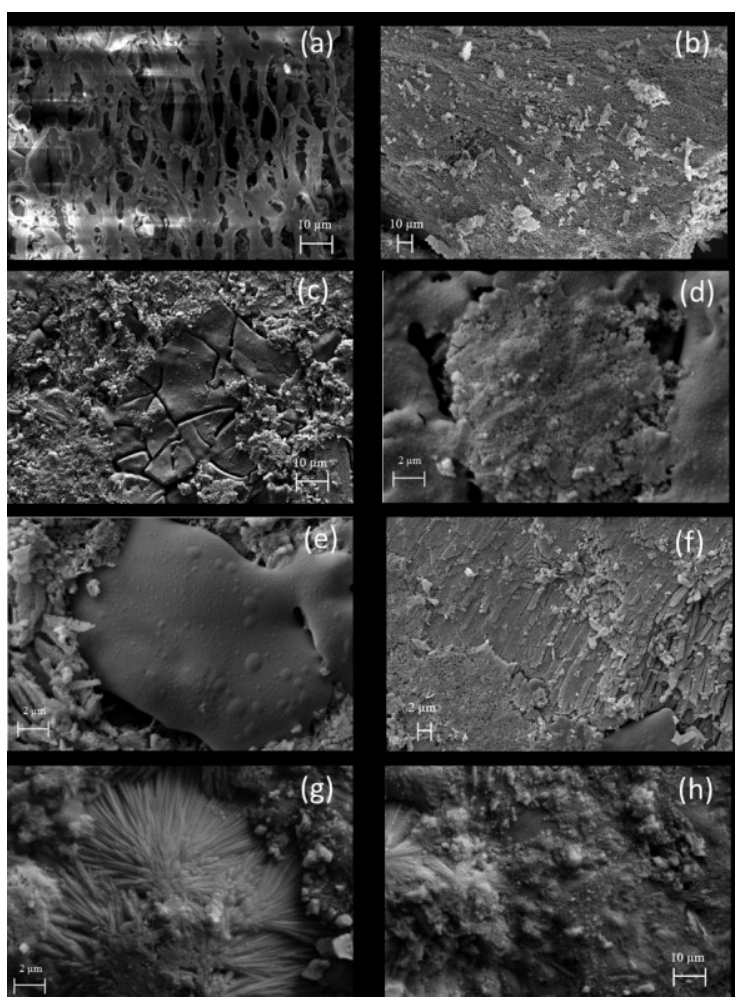

Fig. 2. The SEM images of the (a) TRHA (b) COS before adsorption test, the adsorbent pellet before adsorbed As(III) which prepared from (c) OS $<106 \mu \mathrm{m}$, (d)-(f) OS106-150 $\mu \mathrm{m}$ and $150-250 \mu \mathrm{m}$ and $(\mathrm{g})-(\mathrm{h})$ the adsorbent pellet after adsorbed As(III). 
The SEM image in Fig.2(c) shows that the surface morphologies of the adsorbent pellet prepared from OS size $<106 \mu \mathrm{m}$ before As(III) adsorption test could be divided into two types; the rough one and the plain one. The EDX result (not shown in this paper) indicated that the plain surface morphology should consist of $\mathrm{CaSiO}_{3}$ and $\mathrm{C}-\mathrm{S}-\mathrm{H}$ compounds while the surface morphologies before As(III) adsorption test of the adsorbent pellets prepared from OS sizes 106-150 $\mu \mathrm{m}$ and 150-250 $\mu \mathrm{m}$ were observed in three forms as shown in Figs.2(d) 2(f). The rough surface (Fig.2(d)) and the plain surface (Fig.2(e)) look similar to the surface morphologies of the adsorbent pellet prepared from OS size $<106 \mu \mathrm{m}$ before As(III) adsorption test. However, the third form looks like the layers of porous bars (Fig 2(f)) which is similar to the morphology of COS before As(III) adsorption test (Fig. 2(b)). This implies that some parts of the adsorbent pellet prepared from OS sizes 106-150 $\mu \mathrm{m}$ and 150-250 $\mu \mathrm{m}$ were still in the porous bars form of COS. As mentioned before, the crack of adsorbent pellets prepared from OS sizes 106-150 $\mu \mathrm{m}$ and $150-250 \mu \mathrm{m}$ with ratios between 0.8:0.2 and 0.6:0.4 resulted from the lowering compaction of the precursor powders. During the calcination, $\mathrm{CaCO}_{3}$ changed into $\mathrm{CaO}$ and released $\mathrm{CO}_{2}$ caused the porous structure on the adsorbent surface. Furthermore, the volatile impurity removal and loss of humidity during the calcination caused porosity in the adsorbent pellets. After the adsorbent pellet was added into the solution, the solution could better diffuse into the pores of porous structure in the adsorbent pellets and contact with $\mathrm{CaO}$ inside the adsorbent pellet. The dissolution of $\mathrm{CaO}$ inside the pellet might cause the crack of the adsorbent pellet.

After As(III) adsorption test, the morphologies of adsorbent pellets could be classified into two forms. The first one looks like the needle-like shape as shown in Fig. 2(g). The latter is a plain surface as shown in Fig. 2(h) which looks similar to the plain surface of the adsorbent pellets before As(III) adsorption test (Fig.2 (e)). The needle-like shape morphology on the adsorbent surface looks like the morphology of COS after As(III) adsorption test in the previous work [8]. In addition, Phenrat et al. [16] studied the iron-arsenic sludge immobilized by using cement and lime and found that the needle-like shape was one form of calcium-arsenic compound. The EDX result of needle-like shape morphology (not shown in this paper) showed $\mathrm{Ca}, \mathrm{O}$ and As elements which should refer to Ca-As-O. The SEM result also agrees with the XRD result which indicated that the $\mathrm{As}(\mathrm{III})$ should be adsorbed on $\mathrm{CaO}$ adsorption sites on the surface of adsorbent pellet in the form of CaAs-O. In the case of the plain surface found both before and after adsorption test, this plain surface should be the surface of $\mathrm{CaSiO}_{3}$ and C-S-H compounds which were inactive with As(III) adsorption.

\section{Conclusions}

The adsorbent pellet for As(III) removal was prepared from OS and TRHA. The most appropriate condition to prepare the adsorbent pellet was OS size $<106 \mu \mathrm{m}$ with OS:TRHA ratio of 0.7:0.3 which provided the As(III) maximum capacity of $26.20 \mathrm{mg} / \mathrm{g}$. The adsorbent pellet could be classified into two parts. The first one was the $\mathrm{CaO}$ which could adsorb $\mathrm{As}$ (III) in the form of Ca-As-O. The other one was $\mathrm{CaSiO}_{3}$ and $\mathrm{C}-\mathrm{S}-\mathrm{H}$ compounds which could not adsorb As(III) but could bind the precursor powder to be the stable adsorbent pellet without cracking.

This work is supported by King Mongkut's Institute of Technology Ladkrabang (Grant number KREF015905).

\section{References}

1. Y. Tian, M. Wu, X. Lin, P. Huang,Y. Huang, J. Hazard. Mater., 193, 6, (2011).

2. V.K. Sharma, M. Sohn, Environment International, 35(4), 16, (2009).

3. D. Mohan and C.U. Pittman Jr., J. Hazard. Mater., 142,53 (2007).

4. Y. Du, Q. Lu, H.Chen, Y. Du and D.Du, Journal of Water Process Engineering, 12, 5, (2016).

5. S. Pansamut and G. Wattayakorn, J. Environ. Res. Develop., 4, 8, (2010).

6. P. Pattanapipitpaisal and P. Suraruk, J. Environ. Sci. Eng. Technol., 1, 8, (2012).

7. S.K. Maji, Y.H. Kao and C.W. Liu, Desalination., 280, 7, (2011).

8. P. Khownpurk, W. Wongpromrat, W. ChandraAmbhorn, Key Eng. Mater., 728,7, (2017).

9. J. Prasara-A and S.H. Gheewala, J. Clean. Prod., 167, 8, (2016).

10. S.A. Saad, M.F. Nuruddin, N. Shafiq and M. Ali, Appl. Mech. Mater., 773-774, 4, (2015).

11. A.A. Ramezanianpour, M. Mahdi khani and G. Ahmadibeni, Int. J. Civ. Eng., 7, 8, (2009).

12. G.A. Habeeb and H.B. Mahmud, Mat. Res., 13, 5, (2010).

13. A.B. Srinivasreddy, T.J. McCarthy and E. Lume, 6th Biennial Concrete Institute of Australia's National Conference (Concrete 2013), Australia, 10, (2013).

14. P. Khownpurk and W. Chandra-Ambhorn, JCIE (submitted)

15. A.Seidell, Solubility of inorganic compounds. A compilation of quantitative solubility data from the periodical literature. D. Van Nostrand Company, New York (1919)

16. T. Phenrat, T.F. Marhaba and M. Rachakornkij, J. Hazard. Mater., 118, 10, (2005). 